\title{
A construção da identidade profissional: estudo com gestoras das gerações Baby Boomers, X e Y
}

\author{
Marlene Catarina de Oliveira lopes Melo ${ }^{1}$ \\ Vilma Santos Pereira de Faria ${ }^{1}$ \\ ANA LÚCIA MAGRI LOPES ${ }^{1}$ \\ ${ }^{1}$ Centro Universitário Unihorizontes / Programa de Mestrado em Administração, Belo horizonte - MG, Brasil
}

\begin{abstract}
Resumo
O objetivo deste estudo foi o de analisar a construção da identidade profissional de mulheres pertencentes as gerações Baby Boomers, $\mathrm{X}$ e $\mathrm{Y}$, que atuam como gerentes. Em termos metodológicos, este estudo adotou uma abordagem qualitativa-descritiva e entrevistou 32 mulheres que atuam como gerentes em diversificados setores da economia, localizados na cidade de Belo Horizonte. O grupo entrevistado foi constituído por 6 gestoras da geração Baby Boomers, 11 da geração X e 15 da geração Y. Os dados foram analisados considerando as seguintes categorias propostas por Hill (1993): "aprender o que significa ser gerente", "desenvolver julgamentos interpessoais", "adquirir autoconhecimento", "lutar contra as tensões e emoções" e "gerenciar as transformações". Como principal achado, observou-se que, embora as gerações em estudo apresentem características distintas, como modo de pensar, agir e ver o mundo, tais diferenças pouco interferem no processo de construção da identidade gerencial.
\end{abstract}

Palavras-chave: Identidade profissional. Gerentes. Gerações.

Building professional identity: a study with female managers who are baby boomers, generation Xers, and millennials

\begin{abstract}
This article analyzes the construction of the professional identity of female managers who are baby boomers, generation Xers and millennials. The research adopted a qualitative and analytical descriptive approach, interviewing 32 women working in different sectors of the economy in the city of Belo Horizonte, Brazil. The group interviewed was chosen and divided by generations counting on 06 baby boomers, 11 generation Xers, and 15 Millennials. The data were analyzed considering the dimensions proposed by Hill (1993) when discussing the process of becoming a manager: learning what it means to be a manager; developing interpersonal judgements; gaining self-knowledge; coping with stress and emotions; and managing transformations. The study identified that although the generations have different characteristics (such as way of thinking, acting, and seeing the world), they have little influence in the process of building professional identity of the female managers.
\end{abstract}

Keywords: Professional identity. Managers. Generations.

\section{La construcción de la identidad profesional: una investigación con gerentes femeninos de las generaciones Baby} Boomers, $\mathrm{Xe} \mathrm{Y}$

\section{Resumen}

Este artículo se propuso analizar la construcción de la identidad profesional de las mujeres gerentes pertenecientes a las generaciones Baby Boomers, X e Y. Se aplicó la metodología con abordaje cualitativo-descriptivo. Se entrevistaron 32 gerentes femeninos de sectores diversificados de la economía, de la ciudad de Belo Horizonte, estado de MG. El grupo entrevistado estaba compuesto por 06 gerentes de la generación Baby Boomers, 11 de la generación X y 15 de la generación Y. Los datos se analizaron considerando las categorías propuestas por Hill (1993), a saber: "aprender qué significa ser gerente"; "desarrollar juicios interpersonales"; "adquirir autoconocimiento"; "luchar contra las tensiones y emociones" y, "gestionar las transformaciones". El principal hallazgo fue la percepción de que aunque las generaciones en estudio poseían características diferentes, como: forma de pensar, actuar y ver el mundo, esas diferencias poco interfieren en el proceso de construcción de la identidad gerencial.

Palabras clave: Identidad profesional. Gerentes. Generaciones. 


\section{INTRODUÇÃo}

Ao longo dos anos a função gerencial tem despertado interesse da academia, pois trata-se de uma atividade que, para ser entendida, não basta apenas enunciar suas atribuições. É preciso ir além e compreender suas indagações funcionais, repletas de contradições, ambiguidades e constantes mudanças. É preciso compreender os temas relacionados às dinâmicas e aos conflitos gerados pelo sistema capitalista, as relações de poder no âmbito organizacional, as dificuldades de se estabelecer a harmonia da função gerencial com os assuntos pessoais e familiares, entre outras questões. Ser gerente tem se tornado um desafio, pois os profissionais gerentes estão sempre em situação instável diante dos diversos interesses que permeiam o exercício da função gerencial (VENTURA e MAGESTE, 2016).

Ao assumir a função gerencial, o sujeito inicia um processo de construção de sua identidade profissional por meio de constantes socializações. Isso significa que uma pessoa não constrói sozinha a sua identidade e nem é uma questão de aptidão natural, mas trata-se de um processo construído ao longo da vida pessoal e profissional, constituindo-se como um produto dependente do juízo pessoal e de outros, além da vivência dos relacionamentos, que estão em constante mudança (DUBAR, 2005).

Para Hill $(1993$, p. 6), a identidade profissional é construída socialmente e se apoia em dimensões que se sucedem de maneira sequencial, tais como: "aprender o que significa ser gerente"; "desenvolver julgamentos interpessoais"; "adquirir autoconhecimento"; "lutar contra as tensões e emoções" e "gerenciar as transformações", que são necessárias para o autodesenvolvimento. Dessa forma, considerando que a construção da identidade profissional ocorre por meio das particularidades vividas pelos gestores durante o exercício da função gerencial (HILL, 1993; DUBAR, 2005), este estudo objetivou analisar a construção da identidade profissional de mulheres gerentes das gerações Baby Boomers, $\mathrm{X}$ e $\mathrm{Y}$, com base nestas dimensões. Para tanto, realizou-se uma pesquisa qualitativa e descritiva, por meio de entrevistas com 32 mulheres das gerações Baby Boomers, $\mathrm{X}$ e $\mathrm{Y}$, que ocupam cargos gerencias em organizações do setor público, bancário e tecnológico, na região de Belo Horizonte (MG).

A percepção de diferentes gerações tem sido estudada com o propósito de explicar o comportamento de profissionais e entender suas necessidades, expectativas e aspirações relacionadas à atuação no mercado de trabalho e às mudanças comportamentais que impactam diretamente na estrutura funcional e gerencial dos indivíduos nas organizações (LANCASTER e STILLMAN, 2011). Nesse contexto, pesquisar a construção da identidade profissional de mulheres gestoras, de acordo com as respectivas gerações, contribui para a ampliação e avanços das pesquisas nesse campo de estudo. Desta forma, este artigo foi desenvolvido com a seguinte estrutura: introdução - contextualiza o tema e apresenta o objetivo desta pesquisa; arcabouço teórico - versa sobre a identidade gerencial na perspectiva de Hill (1993); gerações; percurso metodológico; apresentação e análise dos resultados obtidos nas entrevistas; considerações finais, seguidas pelas referências.

\section{COMPLEXIDADE DA FUNÇÃO GERENCIAL}

Estudos referentes à função gerencial não são recentes na Administração, estudos e pesquisas dedicadas a compreensão dos papéis e habilidades gerenciais são desenvolvidas desde o início do século XX (FAYOL, 1964; MINTZBERG, 1973; KOTLER, 1982; HILL, 1993; SILVA, 2008). O ato de dirigir é definido por Fayol (1964) como uma ação que envolve previsão, organização, comando, coordenação e controle. Segundo o autor, a função do dirigente é conduzir a organização de forma que garanta a execução desses cinco aspectos, os quais possibilitam a obtenção de vantagens e a maximização dos recursos da empresa. Percebe-se que, desde a época de Henri Fayol, há mais de cem anos, vêm sendo estudados assuntos referentes à função administrativa, no que diz respeito a planejamento, sistematização, gestão, administração e controle, como meio da concepção especulativa da função gerencial (PAIVA, ÉSTHER, PIRES et al., 2006).

Mintzberg (2010) questiona Fayol quando contrapõe, em sua obra, as funções gerenciais estabelecidas pelo autor, considerando os achados de seu estudo. Os gerentes observados por Mintzberg se sentiram aliviados com a conclusão de seu estudo, pois, para eles, sujeitos da pesquisa de Mintzberg, foram observados em uma situação de cotidiano profissional na qual resolviam um problema atrás do outro para impedirem a desordem organizacional, sem haver uma ordem funcional preestabelecida. Essas características apresentadas por Mintzberg (2010, p. 31) desafiam "alguns de nossos mitos mais queridos sobre a prática da gestão", em que declara que os gerentes não estão o tempo todo planejando, organizando, comandando, coordenando e controlando, como apresentado por Fayol, nos estudos sobre as funções gerenciais. 
Desde a sua primeira obra, Mintzberg (1973) esclarece que o gerente age como um ator social desempenhando três papéis distintos, classificados por ele da seguinte forma: papel interpessoal, papel da informação e papel da decisão. Segundo o autor, o gerente deve ser capaz de exercer essas atribuições de acordo com o que demanda da organização em seu contexto intra e interorganizacional. De igual forma, Hill (1993), em um estudo desenvolvido com gerentes recém-promovidos, apresenta uma posição diferente de Fayol (1964). Ao questionar os novos gerentes sobre o que é ser gerente, a autora não encontrou uma resposta que afirmasse que é "a pessoa no controle". Os profissionais mencionaram que ser gerente é "ser solucionador de impasses, malabarista e artista com capacidade de rápida mudança", aproximando, assim, com o que já dizia Mintzberg (1973): o gerente age como um ator social.

Em outro estudo realizado por Allard-Poesi (2015), os gestores participantes não entraram em consenso a respeito do papel gerencial, semelhantemente ao estudo de Melo (1994). O conceito a respeito da função gerencial, construída pelos gestores participantes apresentou contradições e nuances. $O$ autor observou que até mesmo a definição do papel gerencial é complexa e oscilante entre os próprios profissionais, o que o levou a identificar a seguinte metáfora para a questão gerencial: dancing in the dark. A complexidade da função gerencial exige dos gestores diversas habilidades no exercício funcional e todas elas interferem na construção e manutenção da identidade gerencial. Melo (2002) considera que o gerente ainda precisa exercer uma função política para conciliar os interesses dos grupos, por meio de relações interpessoais e a capacidade de ocultar conflitos.

\section{IDENTIDADE}

A temática "identidade e os processos de identidade" está entre os assuntos mais abordados, debatidos e contestados, no âmbito dos estudos sobre organização e gestão (ALVESSON, ASHCRAFT e THOMAS, 2008; COUPLAND e BROWN, 2012; YBEMA, KEENOY, OSWICK et al. 2009). O processo de formação da identidade gerencial está atrelado a diversos fatores que influenciam, transformam e formam a identidade do indivíduo. Essa construção é influenciada a todo instante pelos fatos diários, religião, relacionamentos sociais estabelecidos, pressões sociais e culturais, expectativas criadas e situação econômica da sociedade, além do bônus e ônus do mundo organizacional. Muitos elementos influenciam na construção dos processos identitários, uma vez que a própria escolha profissional e o exercício da função são responsáveis pela transformação da identidade profissional (RODRIGUES, 2016).

Dubar $(1997,2005)$ apresenta a questão da identidade como algo indissociável entre a identidade para si e a identidade para o outro. Segundo o autor, uma correlaciona-se com a outra, pois o indivíduo sabe quem é, somente pelo olhar do outro. A partir disso, com o somatório das ligações e influências do mundo familiar, social e organizacional, além do próprio interesse e vivência, o sujeito constrói a sua identidade. Ybema, Keenoy, Oswick et al. (2009, p. 301) definem a construção da identidade como "um processo complexo e multifacetado que produz um resultado temporário e negociado socialmente por meio da interação dinâmica entre lutas internas e prescrições externas [...]", visando cada vez mais entender os processos da organização (BROWN, 2001; LOK, 2010). Assim, diante da variedade dinâmica e processual da temática "identidade" e após diversas observações provenientes de perspectivas temporais, históricas, políticas e ontológicas que permitem mudanças identitárias no decurso do tempo, a construção da identidade não pode ser considerada como uma situação inerte (ÉSTHER e MELO, 2008).

\section{Identidade profissional na percepção de Linda Hill}

Os gerentes recentes no exercício da função possuem uma percepção limitada acerca do que vem a ser o cargo de gestor, pois não são considerados capazes de encontrar o sentido e o significado de seu papel. No entanto, concordam que "o papel de gerente é complexo e exigente" (HILL, 1993, p. 11). No exercício da função gerencial, exige-se desses profissionais muito malabarismo em meio a tantas responsabilidades que lhe são impostas, além de estarem constantemente envolvidos com pessoas que apresentam demandas múltiplas e muitas vezes conflitantes. $\mathrm{O}$ indivíduo deixa de ser um mero especialista e executor e transforma-se em uma pessoa que entende melhor a organização, detentora de conhecimento abrangente. A autora considera que, ao assumir a identidade gerencial, o sujeito passa a se preocupar mais com as atividades realizadas pelos outros do que com as suas. 
Por esse motivo, é imprescindível desenvolver as características elementares do papel gerencial, tais como: a capacidade para laborar com redes de trabalho e fazer com que os demais desempenhem suas atividades, interagir com os subordinados, ter visão expandida da organização, trabalhar com o intuito de satisfazer e assimilar as necessidades da rede de trabalho e, naturalmente, apresentar resultados. E, nessa construção da identidade gerencial, acontece uma série de confabulações reais e metafóricas, que sucedem nas cinco dimensões propostas por Hill (1993).

A autora estabelece que a primeira dimensão envolve a aquisição do conhecimento e a percepção que os gerentes têm de suas expectativas pessoais, bem como de seus pares, subordinados e superiores, em razão do exercício da função gerencial. Nessa fase, eles desenvolvem um pensamento mais aberto e estratégico e coletivo, o que gera redes de relacionamentos e prioriza a fixação de agendas. Na segunda dimensão, eles aprendem a lidar com o exercício da autoridade, assim como o ato de controle e delegação, além de desenvolverem a capacidade interpessoal de julgamento.

Na terceira dimensão, eles já passam a obter autoconhecimento, ao entender-se como pessoa e como gerente, tendo consciência de suas forças e fraquezas. Na quarta dimensão, eles compreendem que a liderança de pessoas é mais importante do que as tarefas, consolidando a postura gerencial. Nessa dimensão, os gestores lidam com as tensões do cargo, os conflitos, os medos, as ansiedades e as ambiguidades, que são fontes de estresse, quando se inicia o processo de metamorfose identitária. Finalizando, com a quinta dimensão, a autora debate as formas que contribuem para a transformação do profissional gerente.

Diante disso, Hill (1993) considera que a construção da identidade gerencial inicia-se no primeiro ano da carreira gerencial, com as experiências vivenciadas pelos profissionais. E, no decorrer da vida profissional, os gerentes aprendem a lidar com novas situações, emoções e tensões, que contribuem para o processo de construção e consolidação da identidade gerencial, de acordo com cada geração.

\section{GERAÇõES}

No mercado de trabalho existem diversos grupos de pessoas com características e comportamentos diferentes, o que gera a heterogeneidade dos grupos. Uma das diferenças desses grupos costuma ser o fator idade, responsável pelos comportamentos peculiares em cada faixa etária ou em cada geração (STRAUSS e HOWE, 1991; FALASTER, FERREIRA e REIS, 2015; KRUGER e SAAYMAN, 2015; VELOSO, DUTRA e NAKATA, 2016). Buscando uma melhor compreensão das divergências e convergências dos grupos geracionais e o quanto esses aspectos, de fato, impactam a sociedade contemporânea, o tema "gerações" tem sido estudado com certa recorrência (DANTE e ARROYO, 2017).

A interferência social das gerações se relaciona com as carreiras por elas desenvolvidas e os percursos trilhados de acordo com suas necessidades, perspectivas e pontos de vista. Cada geração apresenta peculiaridades históricas e culturais, assim como perspectivas e interesses distintos (DANTE e ARROYO, 2017). Em virtude das diferentes formas de pensar, agir e ver o mundo, é relevante o estudo de gerações atuantes no mercado de trabalho (COMAZZETTO, VASCONCELLOS, PERRONE et al., 2016). A seguir são descritas algumas características das gerações Baby Boomers, $\mathrm{X}$ e $\mathrm{Y}$.

\section{Baby boomers}

Compreende-se por Baby Boomers os nascidos entre os anos 1946 a 1964, período conhecido como "os anos dourados". De modo geral, os jovens dessa geração presenciaram o princípio da guerra fria e a luta nacionalista no Vietnã (SANTOS, 2011). Essa geração foi batizada como Baby Boomers em razão do cenário positivo pós-guerra, época em que ocorreu um aumento extraordinário na taxa de natalidade global. As crianças que nasceram e viveram nesse período foram submetidas à disciplina rígida nos estudos e no trabalho, e, em obediência aos valores estabelecidos, elas eram recompensadas (OLIVEIRA, 2010).

Entre as características dessa geração, destaca-se o fato de os cidadãos compreenderem que, somente por meio do trabalho, obtém-se ascensão profissional, por isso a necessidade do cumprimento, com exatidão, das obrigações. Os Baby Boomers estão incluídos entre os melhores líderes no contexto empresarial do mundo, em decorrência da capacidade de dirigir os negócios com responsabilidade e cumprir com ética as funções profissionais (OLIVEIRA, 2010; LANCASTER e STILMAN, 2011; VELOSO, DUTRA E NAKATA, 2016). 


\section{Geração X}

A geração X refere-se aos nascidos entre os anos 1965 e 1981, responsáveis por um período de evidentes mudanças, pois se rebelaram contra o que fora estabelecido na época (OLIVEIRA, 2010). As pessoas dessa geração acabaram adotando uma postura de desconfiança por terem crescido em uma época de desenvolvimento do downsizing corporativo. Em razão dessa reestruturação administrativa, a segurança do emprego foi afetada, abalando a crença de que, sendo leais à empresa, os postos de trabalho estavam garantidos.

Essa geração foi impulsionada a desenvolver habilidades que melhorassem a empregabilidade, pois não havia mais a confiança na estabilidade funcional (VELOSO, DUTRA e NAKATA, 2016). A geração Xé constituída de pessoas autônomas, que se importam em fazer a diferença, desde que estejam fazendo o que gostam. Além disso, em razão do desenvolvimento tecnológico, elas não têm paciência com atividades que demandam tempo (BRANCO, 2013).

\section{Geração Y}

A Geração Y compreende os nascidos entre os anos 1982 e 2000, também reconhecida como geração Millennial. No Brasil, à época em que a geração $Y$ começou a desenvolver-se, o país vivia uma substancial instabilidade econômica, seguida do processo de transição democrática, com a publicação da atual constituição federal de 1988. No cenário mundial, prevalecia a cultura da impermanência e a escassez de garantias, com os mercados voláteis (VELOSO, DUTRA e NAKATA, 2016).

A geração Y é considerada aberta à exposição de suas expectativas. As pessoas esperam ascensão profissional imediata e tem o hábito de trocar de empresa com frequência quando não são submetidas a desafios e não tem oportunidade de crescimento profissional na atual ocupação (GRASSI, DE ANDRADE e VELOSO, 2016).

\section{METODOLOGIA}

O estudo realizado apoiou-se em uma pesquisa de abordagem qualitativa e do tipo descritivo analítico (CERVO e BERVIAN, 1983; COLLIS e HUSSEY, 2005), consideradas escolhas adequadas aos objetivos aqui propostos. Os sujeitos da pesquisa foram 32 mulheres gerentes de organizações de setores diversificados da economia localizados na cidade de Belo Horizonte, estado de Minas Gerais. O grupo pesquisado era composto por 10 gerentes do setor de tecnologia, 9 do setor bancário e 13 do setor público. O perfil sociodemográfico das participantes desta pesquisa, nomeadas pela abreviação da palavra entrevistada, " $E$ ", seguida da sequência numeral da quantidade de participantes, E1 a E32, está exposto na Tabela 1 a seguir.

Tabela 1

Identificação por geração E1 - E32

\begin{tabular}{|c|c|c|c|c|}
\hline Gerações & Período de nascimento & Idade atual & Entrevistadas & Total \\
\hline Baby Boomers & De 1946 a 1964 & 54 a 72 anos & E14, E28, E29, E30, E31, E32, & 06 \\
\hline$x$ & De 1965 a 1981 & 37 a 53 anos & $\begin{array}{c}\text { E2, E3, E7, E10, E11, E13, E19, } \\
\text { E21, E23, E24, E26, }\end{array}$ & 11 \\
\hline Y & De 1982 a 2000 & 18 a 36 anos & $\begin{array}{l}\text { E1, E4, E5, E6, E8, E9, E12, E15, } \\
\text { E16, E17, E18, E20, E22, E25, E27 }\end{array}$ & 15 \\
\hline \multicolumn{4}{|l|}{ Total geral } & 32 \\
\hline
\end{tabular}

Fonte: Dados de pesquisa.

As entrevistadas foram separadas de acordo com as respectivas gerações, sendo 6 mulheres da geração Baby Boomers, 11 mulheres da geração $X$ e 15 mulheres da geração $Y$. Em relação ao estado civil, 62,5\% das entrevistadas são casadas, 25\% solteiras e 12,5\% divorciadas. Quanto ao número de filhos, 53\% delas não têm filhos, 28\% têm dois filhos, 16\% um 1 filho. 
Apenas uma das entrevistadas tem três filhos. No que se refere à formação acadêmica, $97 \%$ das entrevistadas têm curso superior e apenas uma só tem o ensino médio. Das mulheres com curso superior, $22 \%$ têm especialização/MBA, 13\% estão com mestrado em andamento e uma concluiu o mestrado.

As entrevistas foram conduzidas com o apoio de um roteiro semiestruturado que contemplava os objetivos específicos do estudo, e foram realizadas de acordo com a disponibilidade de cada uma das mulheres e em local por elas escolhido. Com o consentimento das participantes, as entrevistas foram gravadas e depois transcritas. $O$ critério para escolha das mulheres foi intencional e por acessibilidade (LAVILLE e DIONE, 1999). A unidade de análise constitui-se na relação das entrevistadas com o exercício da prática gerencial no processo da construção identitária.

A análise dos dados coletados passou pelos seguintes processos de tratamento: elaboração das entrevistas, transcrição das gravações, seguindo um roteiro semiestruturado de questões e agrupamento das respostas por categoria, para cada questão. Foi realizado também um tratamento dos conteúdos das entrevistas, que constituiu na tabulação qualitativa, em que ocorrem a identificação e o agrupamento das respostas das entrevistadas conforme o tema da pergunta, e, em seguida, a construção de tabelas. Com os dados tabulados qualitativamente, deu-se a análise temática, baseada nas contribuições de Minayo (2000) e Melo (2002).

Os dados foram organizados em uma planilha que permitiu o agrupamento dos conteúdos mais representativos das respostas, segundo as cinco dimensões de Hill (1993), utilizadas para a análise dos dados obtidos: a. aprendendo o que significa ser gerente; b. desenvolvendo o julgamento interpessoal; c. adquirindo autoconhecimento; d. lidando com as tensões e emoções; e. gerenciando a transformação.

\section{APRESENTAÇÃO E ANÁLISE DOS DADOS}

Os dados da pesquisa foram analisados considerando as cinco dimensões de análise propostas por Hill (1993), que trabalhou com gerentes no seu primeiro ano na função gerencial. Neste estudo, as 32 gerentes entrevistadas apresentaram tempos distintos no cargo: 9 delas tinham até um ano na função, 4 estavam na função até dois anos, 5 estavam na função por um período de três anos, 2 há quatro anos, 1 há cinco anos, 3 há seis anos, 3 há sete anos, 1 exercia o cargo há oito anos, 1 há nove anos, 2 estavam dez anos na função e 1 há 16 anos.

\section{O ser gerente na percepção das entrevistadas}

Segundo Hill (1993), ser gerente consiste em estar preparado para o exercício da função gerencial. Para a autora, é necessário que o gestor compreenda as dificuldades e os prováveis conflitos que cercam o exercício do cargo, ou seja, envolve um processo de aprendizagem. As entrevistadas, tanto da geração Baby Boomers quanto da $\mathrm{X}$ e $\mathrm{Y}$ estão de acordo quanto à função gerencial: trata-se de um cargo de muita responsabilidade. $O$ grupo entrevistado destacou ainda que há necessidade de adquirir conhecimentos diversos para o exercício da função gerencial, como constatado nos extratos de suas falas, a seguir.

Muita responsabilidade (...) saber se relacionar, saber lidar com os problemas do dia a dia (...) lidar com as pessoas, saber delegar [...] (E31/ GERAÇÃO BABY BOOMERS).

[...] representa responsabilidade (...) conhecer muito bem cada um, as competências de cada um e explorar da melhor forma possível o talento que cada um tem (...) dando exemplo (...) ser líder representa essa oportunidade de estar também participando das decisões que a empresa vai tomar [...] (E3/ GERAÇÃO X).

[...] Ser gerente é uma responsabilidade extrema (...) os clientes sempre têm você como referência, tanto para coisas muito boas, tanto para coisas muito ruins, então, assim ser gerente é uma responsabilidade muito grande [...] (E9/ GERAÇÃO Y).

Nessa percepção, com o desenvolvimento da função gerencial, surge a necessidade de desenvolver outras características, consideradas comuns para desempenhar o papel de gestor, tais como: laborar com redes de trabalho, interagir-se bem com os subordinados, ter visão expandida da organização, trabalhar com o intuito de satisfazer e assimilar as necessidades da 
rede de trabalho (HILL, 1993). Características estas apresentadas pelo grupo pesquisado como a definição do ser gerente, ou seja, as entrevistadas veem a urgência de realizar múltiplas funções no exercício da gerência, como: manter a equipe unida e produtiva, estar em dia com os acontecimentos diários, manter contato com outras instituições do mesmo nível, entre outras.

[...] uma consequência de uma carreira construída de anos, né... de trabalho, ela não veio por um acaso, ela foi uma construção (...) através deste cargo eu sou capaz de exercitar um lado que eu gosto muito que é o de ajudar as pessoas [...] (E30/ GERAÇÃO BABY BOOMERS).

[...] Gostar do que faz (...) gostar de pessoas, eu falo empatia (E7/ GERAÇÃO X).

É muito importante (...). Subsidia a minha vida (...) a minha sobrevivência, meus projetos, meus momentos de lazer. [...] (E18/ GERAÇÃO Y).

Percebeu-se, na análise dessa categoria, que, em relação à percepção do que é "Ser Gerente", o princípio "responsabilidade" foi mencionado pelas gerações Baby Boomers, X e Y.. No entanto, observou-se que o posicionamento das entrevistadas mostra estágios diferentes do que é ser gerente, o que reflete o tempo de exercício no cargo e indica que a função exige um processo de aprendizagem constante e evolutivo, reverberando na construção da identidade profissional do gerente.

Pelo extrato da entrevista da E30, pertencente à geração Baby Boomers, observou-se que ela concilia a função "ser gerente" ao processo de "uma carreira construída de anos". Fica expresso na fala da entrevistada o processo de configuração da identidade do profissional gerente. As mulheres da geração $X$ e $Y$ veem no exercício do cargo, um meio de realização pessoal e busca de seus objetivos em todos os âmbitos. Mas admitem que é preciso gostar do que faz.

\section{Desenvolvendo o julgamento interpessoal}

Nessa dimensão, segundo Hill (1993), os gerentes aprendem a exercer a autoridade sem o apoio específico da autoridade formal, além disso, desenvolvem o ato de controle e delegação e são capacitados a desenvolver o julgamento interpessoal. Segundo as entrevistadas é fundamental desenvolver com a equipe de trabalho, um relacionamento interpessoal que envolva clareza na comunicação, flexibilidade, humildade e humanidade, uma vez que, para exercer a função gerencial, é preciso gostar de pessoas.

[...] lidar com as pessoas (...) a clareza da comunicação, uma escuta qualificada, também a clareza da missão, você ter um papel de liderança legal e não de autoridade [...] (E30/ GERAÇÃO BABY BOOMERS).

[...] humildade (...) ter esse feeling pra aprender (...) saber escutar, saber ponderar, não ser impulsivo (...) ter conhecimento (...) ter humanidade (...) ser correto (...) ser justo [...] (E13/ GERAÇÃO X).

[...] é respeito, é você saber compreender, saber escutar, falar de forma mais sensata [...] (E9/ GERAÇÃO Y).

Neste contexto, Rodrigues (2016) esclarece que o processo de formação da identidade profissional sofre várias influências, a todo instante, entre elas, os fatos diários e as implicações dos relacionamentos estabelecidos. Também Dubar (2005) apresenta como um dos elementos da construção da identidade gerencial os resultados dos relacionamentos vividos e o juízo tanto pessoal quanto interpessoal. Embora as gestoras considerem a importância de desenvolver com a equipe de trabalho um bom relacionamento interpessoal, demonstrando respeito, humildade, compreensão, diálogo, entre outras características, elas consideram que a função gerencial demanda pulso firme, porém, com flexibilidade, quando necessário.

[...] A gente tem que ter pulso firme, você tem que conhecer o seu ambiente de trabalho, conhecer as pessoas, você tem que ser firme nas suas decisões, mas também tem que ser uma pessoa flexível [...] (E28/ GERAÇÃO BABY BOOMERS).

[...] saber trabalhar em equipe, ter uma boa comunicação, um bom relacionamento interpessoal, uma comunicação verbal clara, ter realmente facilidade para tomar decisões (...) é flexibilidade [...] (E3/ GERAÇÃO X).

(...) a gente tem que ter muito pé no chão (...) pra gente conseguir ter essa autoridade, fazer o gerenciamento do setor, essa gestão, eu tenho que ter uma estrutura adequada pra isso, não adianta querer só ser autoridade, ser a gestora sem ouvir as pessoas, sem ter esse bom relacionamento (E12/ GERAÇÃO Y). 
Observou-se, na segunda categoria de análise, que todas as gerações em estudo priorizam o bom relacionamento com a equipe de trabalho, na busca pelo respeito mútuo, e apontam o exercício da autoridade sobre os subordinados. As gestoras das gerações analisadas citaram que há necessidade de agir não apenas com firmeza em suas decisões, mas com respeito, flexibilidade e compreensão, pois gerenciar pessoas, respeitando as diferenças, conquista a credibilidade da equipe. Como apresentado pela Hill (1993), os gerentes buscam interagir bem com os subordinados, e Melo (2002) considera que o gerente deva exercer uma função política para conciliar interesses por meio de suas relações interpessoais.

A assunção da identidade "ser gerente" passa pela dualidade do bom relacionamento, mas também pela prática da autoridade. Na geração Y, o exercício da autoridade não é colocado de forma objetiva no discurso. É reconhecida a sua necessidade, mas ainda não é explicitada formalmente a sua prática. A geração reflete, de certa forma, o tempo no cargo. E a expressão metafórica da identidade gerencial pode ser formulada no "estou sendo gerente". Na geração X, há a manifestação do exercício da autoridade por meio do processo de tomada de decisões, que sintetiza a capacidade e a responsabilidade gerencial. A metáfora é colocada na expressão "eu já sou gerente". Finalmente, a gerente da geração Baby Boomers já incorporou a identidade gerencial e coloca com mais clareza a metáfora identitária: "eu sei ser gerente".

\section{O autoconhecimento no gerenciamento}

Na terceira dimensão, Hill (1993) define o autoconhecimento. Essa dimensão envolve o conhecimento que cada gerente tem em relação às suas limitações, tanto como gerente, quanto como pessoa. Nessa perspectiva, os gerentes em início de carreira não têm ideia do que é ser gerente, no entanto, com o passar dos anos, eles se transformam de meros especialistas a profissionais que dominam bem os assuntos pertinentes à organização em que atuam.

Percebeu-se aqui que, embora na análise do ponto anterior as gerentes defendem que a função gerencial exige um bom desenvolvimento das relações interpessoais para o alcance de resultados positivos, elas apresentam esse relacionamento pessoal como o maior dificultador da função.

[...] Uma das maiores dificuldades que a gente encontra na área da gestão é sempre com relação às pessoas, é a área mais delicada. [...] (E30/ GERAÇÃO BABY BOOMERS).

[...] das pessoas aceitarem essa minha forma de ser e de enxergarem a gerência com outro olhar. (...) por ser nova em comparação com outras gerentes [...] (E24/ GERAÇÃO X).

[...] é um pouco difícil de estabelecer essa relação hierárquica, internamente, dentro da empresa (E4/ GERAÇÃO Y).

Ventura e Mageste (2016) lembram que ser gerente é um desafio, pois esse tipo de profissional está sempre diante de situações instáveis e diversos interesses envolvidos. Na função gerencial, é necessário compreender os assuntos referentes à relação de poder no âmbito das organizações, aos contratempos de harmonia da função gerencial com os assuntos pessoais e familiares, entre outras questões.

\section{A luta contra as tensões e emoções}

A quarta dimensão de análise trata da fase em que os gestores estão mais experientes em relação ao exercício do cargo gerencial, pois já vivenciam os dilemas e as fontes de estresse da função (HILL, 1993). No entanto, os geradores de tensão são intrínsecos ao papel gerencial, e, nesse caso, observou-se nos dados analisados, que as entrevistadas sofrem essa tensão em distintas situações no dia a dia.

(...) Está na pressão, está na quantidade... na diversidade de tarefas (...) pessoas que você tem que lidar com elas. (...) (E14/ GERAÇÃO BABY BOOMERS).

(...) é entregar o resultado esperado é o trabalho de gestão de pessoas satisfatório (...) (E3/ GERAÇÃO X).

O stress, o tempo, a pressão, o agora. Se aparece uma demanda rápida de uma hora pra outra e a dificuldade de fazer isso tudo num tempo curto e com qualidade (...) a gente nunca vai ter certeza do que o outro vai responder, porque é imprevisível (...) (E5/ GERAÇÃO Y). 
Nos extratos das falas, observa-se que a autocobrança pelo resultado é algo que incomoda as gestoras. Todas as mulheres pesquisadas demonstraram que sentem tensão diante da cobrança de atingir o resultado esperado, para si e para o outro: "A gente nunca vai ter certeza do que o outro vai responder, porque é imprevisível" (E5/ GERAÇÃO Y). Dubar (2005) confirma que a construção da identidade é produto dependente do juízo pessoal e de outros. Analisando essa temática, percebeu-se que o alcance das metas e a apresentação dos resultados tempestivamente, são fatores de tensão e estresse das mulheres das gerações Baby Boomers, X e Y, no exercício da função gerencial.

Além disso, identificou-se neste estudo, como fonte de tensão das entrevistas, diversos temas, entre os mais citados estão a falta de recursos da organização, metas não alcançadas, sobrecarga de atividades e relacionamentos interpessoais. Nesse contexto, Ybema, Keenoy, Oswick et al. (2009) idealizam que a construção da identidade gerencial é um processo complexo, repleto de facetas, que apresenta resultado temporário, negociado socialmente, mediante o convívio dinâmico de lutas internas e obrigações externas. Ressalta-se aqui que, mesmo em outro ponto da entrevista, as gerentes citaram as dificuldades de relacionamento no exercício da função gerencial. Nesse contexto, Dubar (2005) evidencia que, além de a construção da identidade gerencial ser resultado de juízo pessoal e dos outros, ela é produto da vivência dos relacionamentos, os quais estão em constante mudança.

\section{O gerenciamento das transformações}

Na dimensão o gerenciamento das transformações, os gestores apresentam como se dá o processo de mudança do profissional executor para o profissional gerente. Nessa categoria, segundo Hill (1993), o indivíduo deixa de ser um simples executador de tarefas e assume uma postura gerencial, mantendo a visão ampla da organização. Para as gerações representadas neste estudo, o gestor administra essa transformação constantemente por meio das atualizações e da busca por mais conhecimento formal, além disso, as entrevistadas consideram importante estabelecer uma rede de contatos. Como se observa nos extratos de fala a seguir:

[...] tem que buscar muito contato (...) tem que estar sempre estudando e se atualizando [...] (E14/ GERAÇÃO BABY BOOMERS).

[...] estudando, pesquisando, internet, vendo um caso aqui, o que é isso ali, trocando ideias com outros gestores [...] (E2/ GERAÇÃO X).

[...] É sempre buscar o que está saindo de novo (...) agora estou fazendo um novo MBA em negócios (...) estudar, pesquisar (...) absorver o que ele (o chefe) me fala, porque eu acho que eu aprendo muito [...] (E6/ GERAÇÃO Y).

No processo de gerenciamento da transformação e construção da identidade gerencial, as entrevistadas consideram que é fundamental aprender com os problemas do dia a dia, assim como buscar, quando possível, suporte em seus pares, visando sempre um diálogo aberto com a equipe de trabalho. Quando citou as funções gerencias, Fayol (1964) destacou que os gerentes devem procurar obter todas as vantagens possíveis, com todos os recursos que a empresa dispõe, com o propósito de administrar bem a organização.

Com base na análise dessa dimensão, percebeu-se que tanto a geração Baby Boomers, como as gerações X e Y gerenciam o processo de transformação de simples executores de tarefas a gerentes profissionais, buscando atualizações constantes. Trata-se, portanto, de um processo diário, em razão das mudanças que acorrem constantemente em todas as esferas da sociedade. Corroborando, Esther e Melo (2008) esclarecem que a identidade não pode ser considerada uma questão estática, em função das constantes mudanças no âmbito temporal, histórico, político, entre outras. A construção da identidade gerencial, segundo a geração de gestoras pesquisadas, é construída por caminhos diferentes, chegando a uma identidade gerencial semelhante, o que indica que 'o ser gerente' sobrepõe às peculiaridades das características geracionais.

\section{CONSIDERAÇÕES FINAIS}

Este estudo discorreu sobre a construção da identidade gerencial de mulheres gerentes das gerações Baby Boomers, $\mathrm{X}$ e $\mathrm{Y}$ utilizando as dimensões de análise propostas por Hill (1993), as quais são: aprender o que significa ser gerente; desenvolver julgamentos interpessoais; adquirir autoconhecimento; lutar contra as tensões e emoções; gerenciar as transformações. 
Observou-se que as gestoras que participaram do estudo se preocupam com a educação formal, a maioria possui curso superior, com especialização ou mestrado concluídos ou e andamento, além disso, elas expressam por meio de seus depoimentos, acerca da necessidade da atualização constante, como requisito primordial para o exercício da função gerencial. Vale ressaltar que todas essas características foram visualizadas no grupo pesquisado independentemente da geração.

Também se observou que o exercício da função gerencial requer muita responsabilidade, esse aspecto foi amplamente citado por todas as entrevistadas, tanto da geração Baby Boomers, quanto das gerações $\mathrm{X}$ e Y. Embora as gestoras considerem que ser gerente é uma função que exige extrema dedicação, malabarismo no dia a dia, proatividade, entre outras questões, as entrevistadas sentem prazer e se realizam no exercício da função gerencial.

Em relação à dimensão de análise, caracterizada pelo julgamento interpessoal, observou-se que as gerações em estudo não se apoiam exclusivamente na autoridade formal para exercerem a função gerencial. $O$ respeito e a autoridade devem ser conquistados por meio do diálogo e do bom relacionamento em equipe e jamais pela imposição. Ter clareza na comunicação e flexibilidade na tomada de decisões, ser humilde, buscar conhecer os subordinados e jamais ser impulsiva. Aspectos praticamente citados por todas as gerações em estudo.

Na perspectiva de análise autoconhecimento na área gerencial, verifica-se neste ponto da carreira que as gerentes começam a se conhecer tanto como pessoas quanto como gestoras. Nesse aspecto, percebeu-se que a maior dificuldade enfrentada pelas entrevistadas é no tocante aos relacionamentos com os subordinados e seus pares. $O$ grupo pesquisado enfatizou que o relacionamento interpessoal é, sem dúvida, o principal fator de tensão e estresse na organização, além do que, o exercício da profissão apresenta complexidades inimagináveis.

O processo de construção da identidade gerencial envolve uma série de questões, por isso é fundamental que as gestoras desenvolvam habilidades para contornar as situações que surgem no dia a dia e administrarem as transformações necessárias na função gerencial. Nesse ponto, também foi unânime a necessidade de manter-se atualizada e buscar conhecimento tanto formal, com complementação dos estudos acadêmicos, quanto informal, traduzido na busca por boas relações com seus pares, assim como o diálogo aberto com a equipe de trabalho.

Dessa forma, foi possível verificar que a identidade profissional perpassa por diversos problemas, dificuldades, conquistas, sentimentos de realização e dilemas inerentes ao exercício da função gerencial. Observou-se, que, a despeito de as gerações, tanto na perspectiva teórica, quanto nos resultados observados empiricamente, apresentem características distintas, como modo de pensar, agir e ver o mundo, quando relacionadas a construção da identidade e o posicionamento gerencial, exibem evidentes similaridades. Isso significa que a função gerencial apresenta características intrínsecas que se sobrepõem a outras dimensões interligadas ao processo gerencial, o que conduz a conclusão de que as particularidades de cada geração parecem pouco interferir no processo de construção identitária do gerente. 


\section{REFERÊNCIAS}

ALLARD-POESI, F. Dancing in the dark: Making sense of managerial roles during strategic conversations. Scandinavian Journal of Management, v. 31, n. 3, p. 338-350, 2015.

ALVESSON, M.; ASHCRAFT, L. K.; THOMAS, R. Identity matters: Reflections on the construction of identity scholarship in organization studies. Organization, v. 15, n. 1, p. 5-28, 2008.

BRANCO, V. F. C. A gestão da geração Y nas organizações. Rio de Janeiro: Qualitymark, 2013. p. 80.

BROWN, A. D. Organization studies and identity: Towards a research agenda. Human Relations, v. 54, n. 1, p. 113-121, 2001.

CERVO, A. L.; BERVIAN P. A. Metodologia científica. São Paulo: Mc Graw-Hill, 1983. p. 53-59.

COLLIS, J.; HUSSEY, R. Pesquisa em administração: um guia prático para alunos de graduação e pós-graduação. Porto Alegre: Bookman, 2005.

COMAZZETTO, L. R. et al. A geração Y no mercado de trabalho: um estudo comparativo entre gerações. Revista Psicologia: Ciência e Profissão, v. 36, n. 1, p. 145-157, 2016.

COSTA, A. M. N. O campo da Pesquisa Qualitativa e o Método de Explicação do Discurso Subjacentes (MENDS). Pontifícia Universidade Católica do Rio de Janeiro 2007. Disponível em: <www.scielo.br/scielo. php?pid=S0102-79722007000100009\&script=sci_abstract\&tlng=pt>. Acesso em: 18 jul. 2019.

COUPLAND, C.; BROWN, A. D. Identities in action: Processes and outcomes. 2012.

DANTE, F. S.; ARROYO, R. F. Âncoras de carreira: por onde caminham as gerações? Revista de Carreiras e Pessoas (ReCaPe), v. 7, n. 2, p. 512-528, 2017.

DUBAR, C. A socialização: construção das identidades sociais e profissionais. Porto: Porto, 1997.

ÉSTHER, A. B.; MELO, M. C. O. L. A construção da identidade gerencial dos gestores da alta administração de universidade federais em Minas Gerais. Cadernos EBAPE.BR, Rio de Janeiro, v. 6, n. 1, p. 1-17, 2008.

FAYOL, H. J. Administração Industrial e Geral. São Paulo: Atlas, 1964.

FALASTER, C.; FERREIRA P.M.; REIS C. Atributos que atraem a geração $Y$ na escolha do emprego ideal: uma análise a partir da perspectiva de estudantes veteranos. Revista Contemporânea de Economia e Gestão, v. 13, n. 3, p. 2-22, 2015.

GRASSI, J. A.; DE ANDRADE, M. S.; VELOSO, E. F. R. Gestão de gerações em sistemas bancários. Revista Competitividade e Sustentabilidade, v. 3, n. 1, p. 11-27, 2016.

HILL, A. L. Os novos gerentes: assumindo uma nova identidade. São Paulo: Makron Books, 1993.

KOTLER, P. Marketing for Non-profit Organizations. 2. ed. New Jersey: PrenticeHall, 1982.

KRUGER, M.; SAAYMAN, M. Consumer preferences of Generation $Y$ : Evidence from live music tourism event performances in South Africa. Journal of vacation marketing, v. 21, n. 4, p. 366-382, 2015.

LANCASTER, L. C.; STILLMAN, D. O Y da questão: como a geração Y está transformando o mercado de trabalho. São Paulo: Saraiva, 2011.

LAVILLE, C.; DIONNE, J. A construção do saber: manual de metodologia da pesquisa em ciências humanas. Porto Alegre: Artmed; Belo. Horizonte: UFMG 1999.
LOK, J. Institutional logics as identity projects. Academy of Management Journal, v. 53, n. 6, p. 1305-1335, 2010.

MELO, M. C. O. L. Dificuldades de implementação de uma nova função gerencial: alguns resultados e reflexões. Belo Horizonte: CEPEAD/DCA/UFMG, mimeo, 1994.

MELO, M. C. O. L. A gerência feminina em empresas do setor industrial mineiro: inserção, vivência e desafios. 2002. $196 \mathrm{f}$. (Relatório de Pesquisa) - Núcleo de Relações de Trabalho e Tecnologias de Gestão, Universidade Federal de Minas Gerais, Centro Nacional de Desenvolvimento Cientifico e Tecnologia, Belo Horizonte, 2002a.

MELO, M. C. O. L. Reflexividade e a dinâmica da ação gerencial. In (org.). Gerência em ação: singularidades e dilemas do trabalho gerencial. Rio de Janeiro: FGV, 2005.

MINAYO, M. C. S. O desafio do conhecimento: pesquisa qualitativa em saúde. 7. ed. São Paulo: Hucitec; Rio de Janeiro: Abrasco, 2000.

MINTZBERG, $\mathrm{H}$. The nature of managerial work. New York: Haper Row, 1973.

MINTZBERG, H. Managing: desvendando o dia a dia da gestão. Tradução de Francisco Araújo da Costa. Revisão Técnica: Roberto Fachin. Porto Alegre: Bookman, 2010.

OLIVEIRA, S. Geração Y: o nascimento de uma nova versão de líderes. São Paulo. Intregrare, 2010.

PAIVA, K. C. M. et al. Milícias, malícias e delícias da função gerencial: o setor hoteleiro em foco. Turismo em Análise, v. 17, n. esp., p. 116141, jan. 2006.

SILVA, J. R. G. Profissionais qualificados e experiências de autoemprego: questões de tempo e espaço. In: ENCONTRA DA ANPAD, 30., 2008, Salvador. Anais... Salvador: ANPAD, 2008.

VENTURA, R. C. M. O.; MAGESTE, G. S. Trabalho gerencial: uma análise teórica das dimensões que o cercam. In: SEMINÁRIO CIENTíFICO DA FACIG, 2., 2016, Coqueiro. Anais... Coqueiro: FACIG, 2016. Disponível em: <http://pensaracademico.facig.edu.br/index.php/ semiariocientifico/article/view/112/93>. Acesso em: 01. set. 2017.

RODRIGUES, A. B. G. C. Impactos da prática da gestão na identidade de um docente do ensino superior. In: ENCONTRO INTERNACIONAL DE FORMAÇÃO DE PROFESSORES, 9., 2016, Sergipe. Anais... Sergipe: ENFOPE, 2016.

SANTOS, A. L. A Geração Y nas organizações complexas: um estudo exploratório sobre a gestão dos jovens nas empresas. 2012. Dissertação (Mestrado em Administração) - Faculdade de Economia, Administração e Contabilidade, Universidade de São Paulo, São Paulo, 2012. Disponível em: <www.teses.usp.br/teses/ disponiveis/12/12139/tde-30032012-153841/pt-br.php>. Acesso em: 12 jun. 2017.

STRAUSS, W.; HOWE, N. Generations: the history of America's future, 1584 to 2069. New York: William Morrow and Company, 1991.

VELOSO; E. F. R.; DUTRA, J. S.; NAKATA, L. E. Percepção sobre carreiras inteligentes: diferenças entre as gerações $Y, X$ e Baby Boomers. REGE - Revista de Gestão, São Paulo, v. 23, n. 2, p. 88- 98, 2016.

YBEMA, S. et al. Articulating identities. Human Relations, v. 62, n. 3, p. 299-322, 2009. 
Marlene Catarina de Oliveira Lopes Melo

ORCID: https://orcid.org/0000-0002-9194-698X

Bolsista Sênior do CNPq; Professora Titular do Centro Universitário Unihorizontes; Professora Titular aposentada da UFMG; Reitora do Centro Universitário Unihorizontes; Doutora em Ciências das Organizações pela Université Paris IX - Dauphine - França, mestrado em Administração (Administração Geral e Relações Industriais) pelo Departamento de Ciências Administrativas da UFMG, especialização - Diploma de Estudos Aprofundados - DEA, pela Université Paris IX-Dauphine- França, e bacharelado em Comunicação Social- Jornalismo pela Faculdade de Filosofia e Ciências Humanas da Universidade Federal de Minas Gerais (UFMG); Coordenadora do Núcleo de Relações de Trabalho e Tecnologia de Gestão NURTEG, Belo Horizonte-MG, Brasil. E-mail: marlene.catarina@unihorizontes.br

Vilma Santos Pereira de Faria

ORCID: https://orcid.org/0000-0002-0293-120X

Mestre em Administração e bacharel em Ciências Contábeis pelo Centro Universitário Unihorizontes; Atualmente é professora Universitária e pesquisadora do Núcleo de Relações de Trabalho e Tecnologias de Gestão - NURTEG, Belo Horizonte - MG, Brasil. E-mail: vilma.santos@unihorizontes.br

\section{Ana Lúcia Magri Lopes}

ORCID: https://orcid.org/0000-0001-6012-9621

Mestre em Administração e bacharel em Administração pelo Centro Universitário Unihorizontes; É Coordenadora de Avaliação Institucional e membro da CPA do Unihorizontes; Professora Universitária e pesquisadora do Núcleo de Relações de Trabalho e Tecnologias de Gestão - NURTEG, Belo Horizonte-MG, Brasil. E-mail: ana.lopes@unihorizontes.br 